\title{
Adsorption of nickel on electric arc furnace slag: batch and column studies
}

\begin{abstract}
The ability of electric arc furnace slag (EAFS), a by-product of the steel industry to adsorb nickel $[\mathrm{Ni}(\mathrm{II})]$ from an aqueous solution, was investigated by both batch and column operations. The characterization studies showed the mesoporous nature of EAFS with dominance of acidic sites. The adsorption was found to be dependent on the adsorbent dosage, contact time, the $\mathrm{pH}$, and initial metal ion concentration. Optimum $\mathrm{Ni}$ (II) uptake was $160.92 \mathrm{mg} / \mathrm{g}$ at $1000 \mathrm{mg} / \mathrm{L}$ initial concentration with equilibration time $216 \mathrm{~h}$. Adsorption follows the pseudo-second-order kinetics model. Linear and non-linear isotherm models revealed the applicability of the Langmuir model confirming monolayer adsorption. Both the column bed capacity and the exhaustion time increased with increase in bed height. The saturation time was found to increase from 42 to $46 \mathrm{~h}$ with a decrease in the flow rate from 15 to $5 \mathrm{~mL} / \mathrm{min}$. The bed depth saturation time and Thomas models were evaluated. The experimental breakthrough curves agreed well with the predicted model.
\end{abstract}

Keyword: Batch and column process; Chemisorption; Electric arc furnace slag; Nickel; Thomas model 